\title{
The research and simulation on passive solar house with the attached
}

\section{sunspace in Beijing}

\author{
Qiao Chunzhen ${ }^{1, a} \quad$ Zhao Yuqing ${ }^{2, b} \quad Y u T^{3, c} \quad \mathrm{Ge} \mathrm{Ai}^{4, \mathrm{~d}}$ \\ $\left({ }^{1,2,3,4}\right.$ College of Civil Engineering, North China University of Technology, Beijing 100144, China ) \\ a,c,djoecz1221@sina.com bzyqbj@126.com
}

Keywords: Attached sunspace; Solar house; energy saving rate

Abstract: Through carrying out experiment and test on sunspaces-attaching passive solar house and thereference room seated in the cold region of north China, under the same condition of these two's initial status, energy-saving effect of solar house under different operation modes has been analyzed in this paper. Besides, the reliability of DeST-h software to solar house and the reference room has been verified. By simulating the most optimized operation mode of solar house on this base, heating energy saving rate of such solar house has been calculated and analyzed. The results can provide references for solar heating in the northern suburbs.

\section{Introduction}

With the implementation of new rural construction, rural residential area has been increased with years. Heating energy consumption of heating farmhouse has been on the high side with heating coal consumption quantity per unit area reaching $33.5 \mathrm{~kg}$ of standard coal[1-3]. Peasant households have undertaken heavy economic burden in the aspect of fuel expense. Thus, under the current circumstances that energy is being increasingly scarce, it has been an urgent issue to be addressed of improving energy saving rate of rural construction heating[4-6].

As a kind of construction which can efficiently take advantage of solar energy, sunspaces-attaching passive solar house is important implication to resolve rural heating consumption in the cold region of north China. It has attracted extensive attention since many years ago[7-9]. In allusion to sunspaces-attaching passive solar house in Beijing rural area (hereafter referred to as "solar house"), this paper, through selecting a reference room which has same geological location, construction area, structure, constituent material and architectural composition with solar house, has carried out comparison between these two different constructions. By analyzing and calculating relevant data, it has provided the best optimized implementation way, which can offer a reference to solar house's large-scale application and popularization in the cold region of north China.

\section{Test and analysis of solar house energy saving experiment}

\section{General situation of construction}

The solar house and reference room in this paper are located in Liuduhe Village, Bohai Town, Huairou District in Beijing. Their floor plan and south elevation are as shown in figure 1. Architectural form is single-layer dwelling. Bottom of the floor has adopted $50 \mathrm{~cm} * 50 \mathrm{~cm}$ reinforced concrete columns to support with floor height being $3 \mathrm{~m}$ and covered area $59.5 \mathrm{~m}^{2}$. Buildings face south. Solar house's south window area is $18.2 \mathrm{~m}^{2}$; Window C1's finalized size is $1.5 \mathrm{~m} * 1.2 \mathrm{~m}$, window $\mathrm{C} 2$ is $0.8 \mathrm{~m} * 0.45 \mathrm{~m}$ with heat transfer coefficient of $5.70 \mathrm{~W} / \mathrm{m}^{2} \mathrm{~K}$; The finalized size of door 
M1 and M3 are respectively $1 \mathrm{~m} * 2 \mathrm{~m}$ and $2 \mathrm{~m} * 2 \mathrm{~m}$, M2 is $0.8 \mathrm{~m} * 1.9 \mathrm{~m}$ with heat transfer coefficient of $5.70 \mathrm{~W} / \mathrm{m}^{2} \mathrm{~K}$; South wall is 37 brick wall with heat transfer coefficient of $1.55 \mathrm{~W} / \mathrm{m}^{2} \mathrm{~K}$. The rest of the wall is 37 brick wall $+5 \mathrm{~cm}$ extruded sheet external thermal insulation with the coefficient 0.4 $\mathrm{W} / \mathrm{m}^{2} \mathrm{~K}$; interior wall is 24 brick wall with heat transfer coefficient of $1.73 \mathrm{~W} / \mathrm{m}^{2} \mathrm{~K}$; layer is pre-stressed concrete hollow-core slabs with coefficient $3.16 \mathrm{~W} / \mathrm{m}^{2} \mathrm{~K}$; roofing is $12 \mathrm{~cm}$ reinforced concrete $+15 \mathrm{~cm}$ polystyrene particles insulation layer + waterproof layer with coefficient of 0.35 $\mathrm{W} / \mathrm{m}^{2} \mathrm{~K}$.
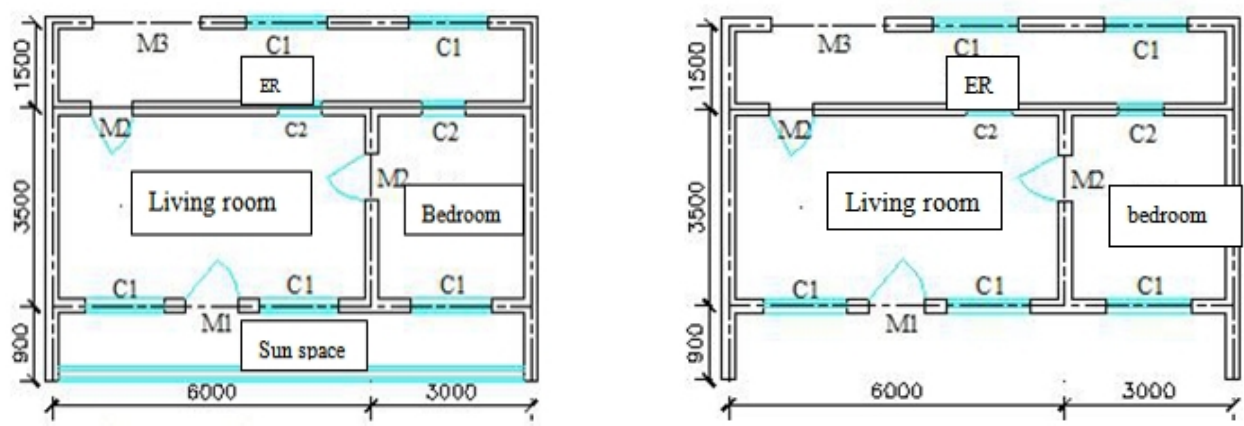

Fig.1 Building Plans Sun Room and the Reference Room

\section{The identity test of initial condition of solar house and reference room}

Through judging indoor temperature, black globe temperature, and room ventilation rate of solar house and reference room, we can judge whether their initial conditions are the same or not. The test result of indoor temperature and black globe temperature of these two constructions are as shown in figure 3 and 4.

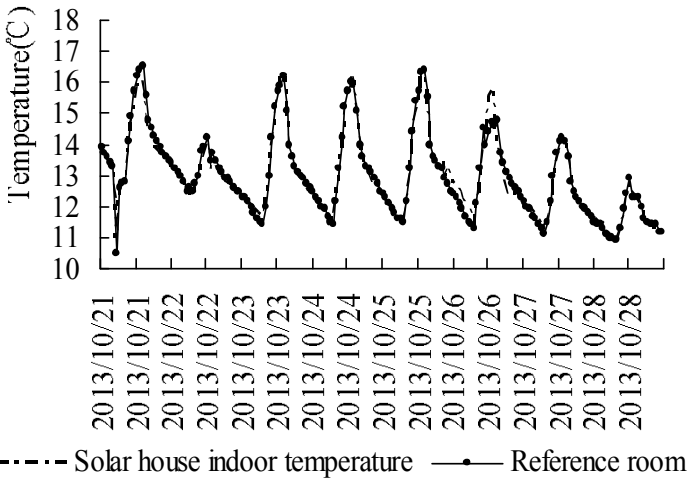

Fig. 2 Comparison of Solar House and Real Indoor Temperature

Adopt tracer gas measuring to test room ventilation quantity. Select $\mathrm{CO} 2$ as tracer gas to test ventilation rate of the sun room and reference room. The result is as shown in figure 5 . 


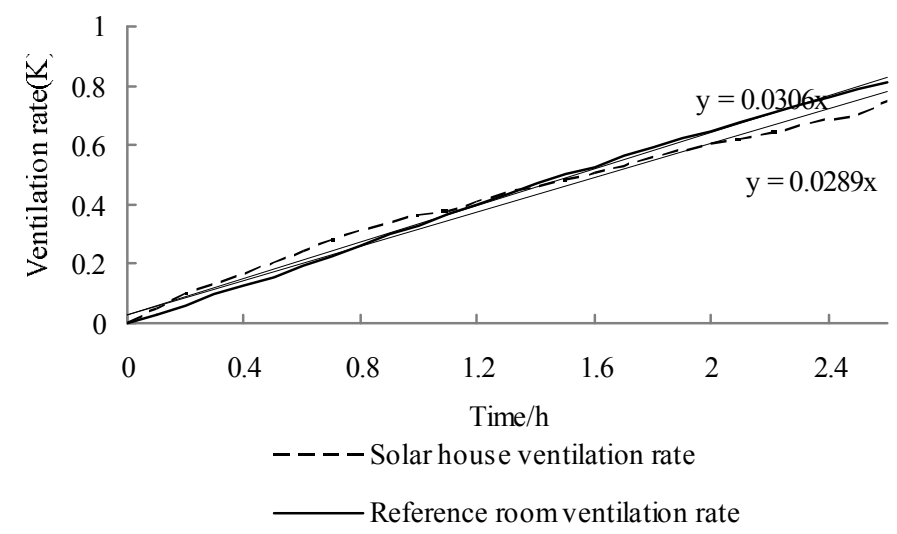

Fig. 4 the Sun Room and the Reference Room Ventilation

From figure 2, 3 and 4, we can see that the sun room and reference room have same initial conditions in the aspects of indoor temperature, black globe temperature and ventilation rate.

\section{The test of sun room under different operation modes}

Before testing, install south windows and radiation protection insulation curtains in the sun room on November 2nd. During testing process, close doors and windows of the reference room and ensure that there's no heat source in sun room and reference room.

Table 1 The Real test Content

\begin{tabular}{|l|l|l|}
\hline & \multicolumn{1}{|c|}{ date } & \multicolumn{1}{|c|}{ Test content } \\
\hline Mode 1 & $11.11-11.12$ & Open curtain, 8:00-16:00 open public wall window \\
\hline Mode 2 & $11.14-11.16$ & 8:00-16:00 open curtain, close public wall window \\
\hline Mode 3 & $11.17-11.19$ & 8:00-16:00 open curtain and public wall window \\
\hline Mode 4 & $12.1-12.3$ & Open curtain, close public wall window \\
\hline
\end{tabular}
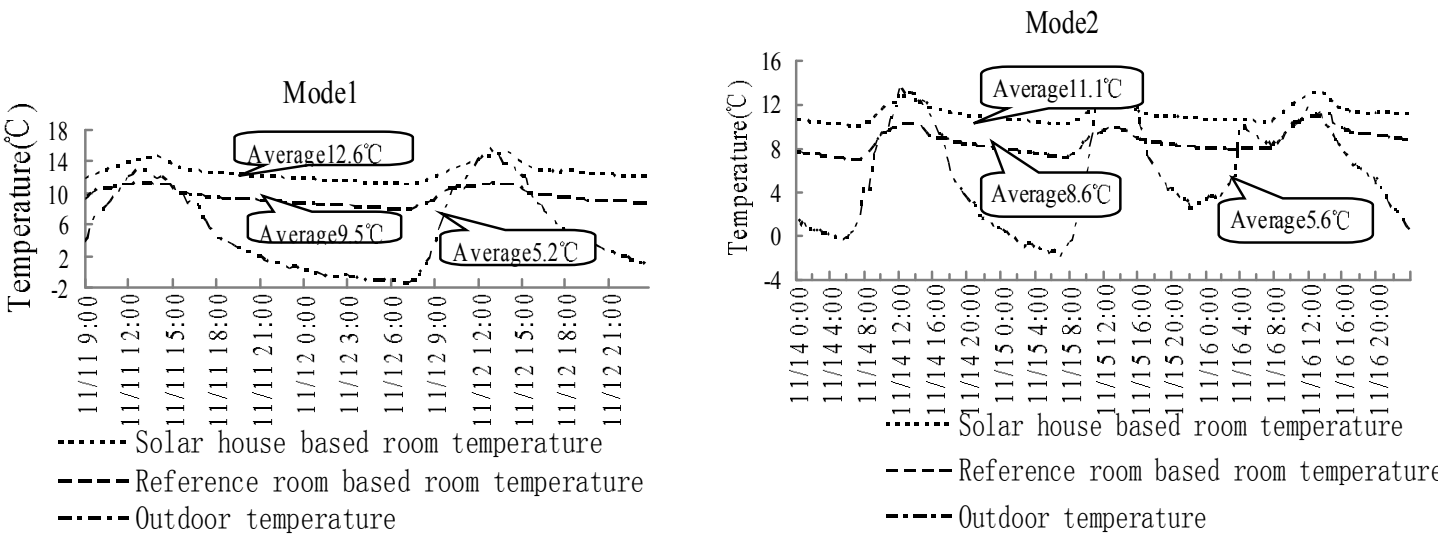

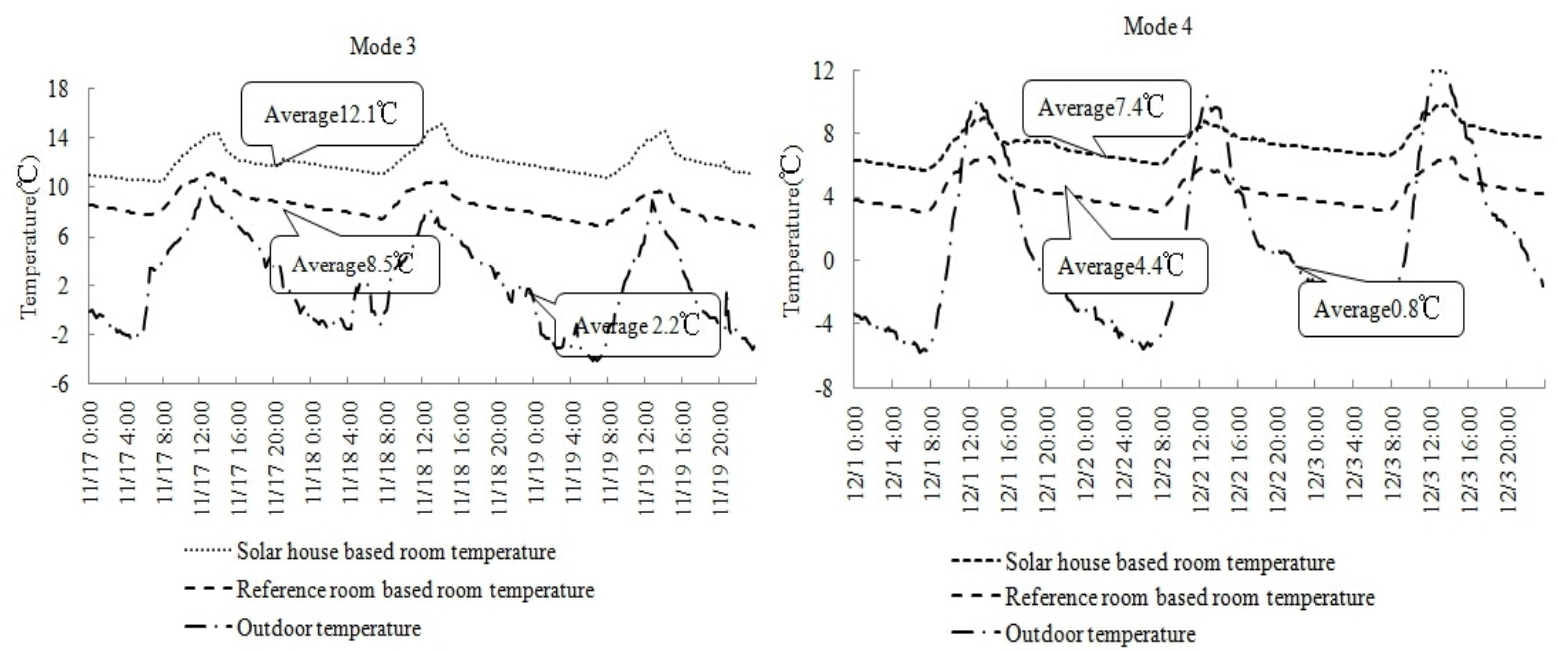

Fig. 5 Different Modes of Solar House and the Reference Room Based on Measured at Room Temperature

During the process of experiment, the total radiation per unit area on solar day under different modes are respectively $376 \mathrm{~W} / \mathrm{m}^{2} 、 335 \mathrm{~W} / \mathrm{m}^{2} 、 340 \mathrm{~W} / \mathrm{m}^{2} 、 330 \mathrm{~W} / \mathrm{m}^{2}$. From figure 5 and 6 , we can draw the conclusion that the basic room temperature difference of solar room and reference room under mode 3 is the largest. However, in the experimental stage, as time goes after increasing sun space, the construction can store heat. Mode 1 has exerted some influence on mode 3's operation result. Compared with the mode 3, mode 1 can better explain energy saving contribution rate of the sun space. The optimized operation mode of sun space needs further simulation and analysis.

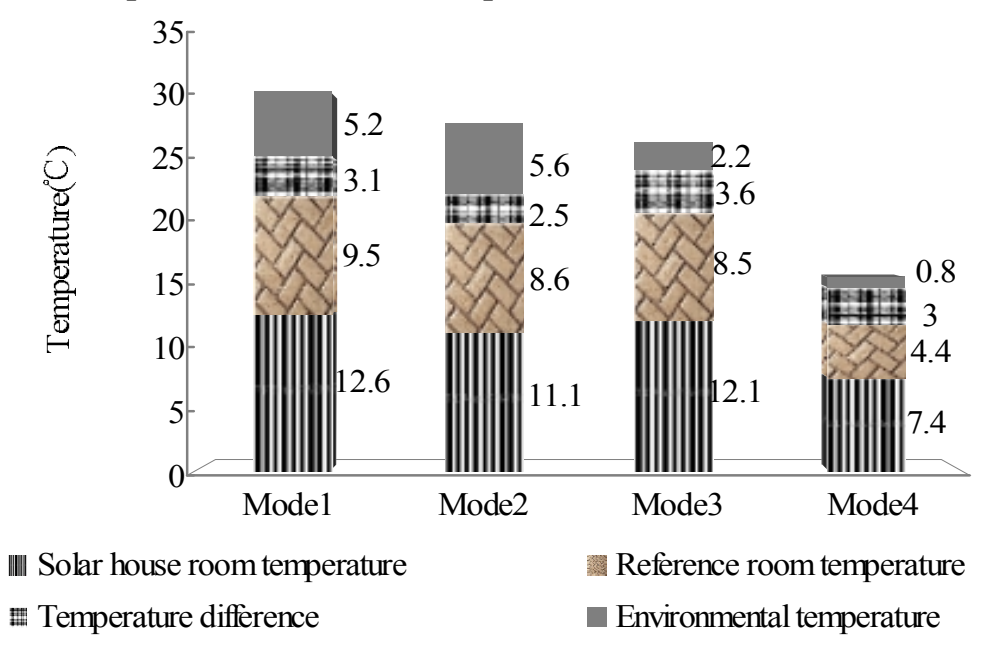

Fig.6 Solar House and Real Test Results Contrast

\section{Dynamic simulation analysis of construction}

This paper has made use of hourly meteorological parameters in typical year provided by DeST for simulation and analysis of sun space under different working condition.

According to the verified simulation reliability of DeST, simulate basic room temperature of the solar room under four operation modes. Area is in Beijing and time period is from December 20th to December 25th selected from DeST database, as Fig 8 . These days are all sunny days with total solar radiation per day on horizontal surface respectively as $7.7 \mathrm{MJ} / \mathrm{M}^{2} \cdot \mathrm{d}, 9.2 \mathrm{MJ} / \mathrm{M}^{2} \cdot \mathrm{d}, 8.5 \mathrm{MJ} / \mathrm{M}^{2} \cdot \mathrm{d}$, $7.7 \mathrm{MJ} / \mathrm{M}^{2} \cdot \mathrm{d}$. 


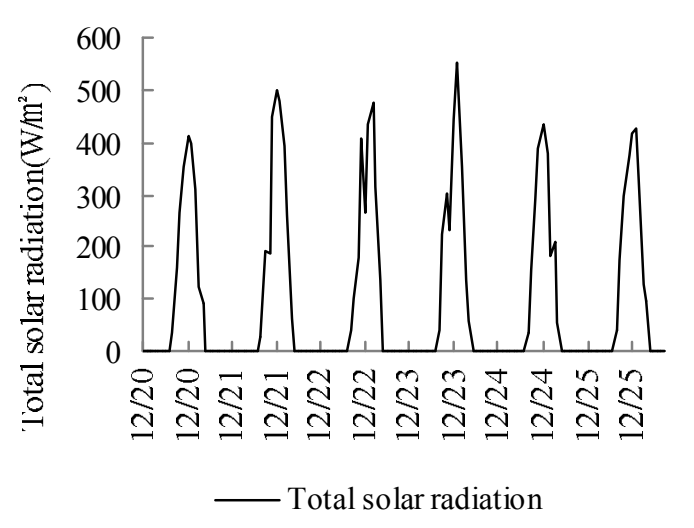

Fig. 7 the Total Solar Radiation in Beijing during Simulation

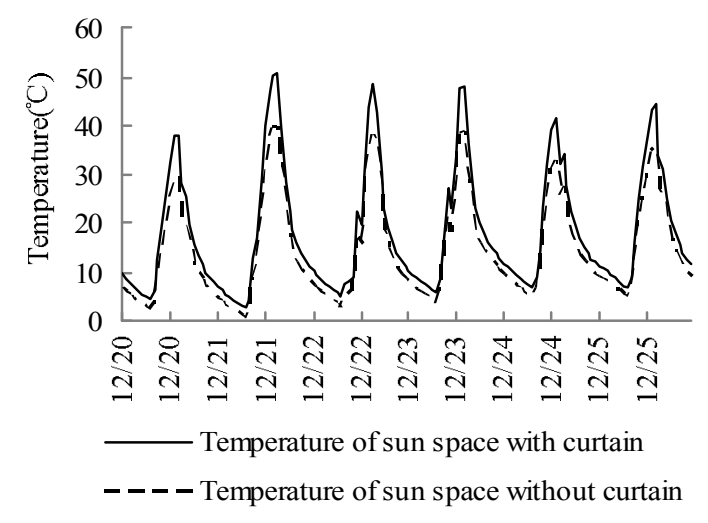

Fig. 8 the Sun without Curtains Temperature

From figure 8 and 9, we can see that when there's curtain and no curtain in the sun space of solar house, its temperature is respectively $17.9{ }^{\circ} \mathrm{C}$ and $13.8{ }^{\circ} \mathrm{C}$. Installing curtain in the sun space can reduce heat lose and improve its temperature; The average values of based room temperature of mode $1,2,3$, and 4 are respectively $3.3^{\circ} \mathrm{C} 、 1.1^{\circ} \mathrm{C} 、 3.7^{\circ} \mathrm{C} 、 0.2^{\circ} \mathrm{C}$. The solar house's optimized operation mode is installing insulation curtain at night in sun space and increase ventilation of indoor rooms and sun space when operating on sunny days in winter.

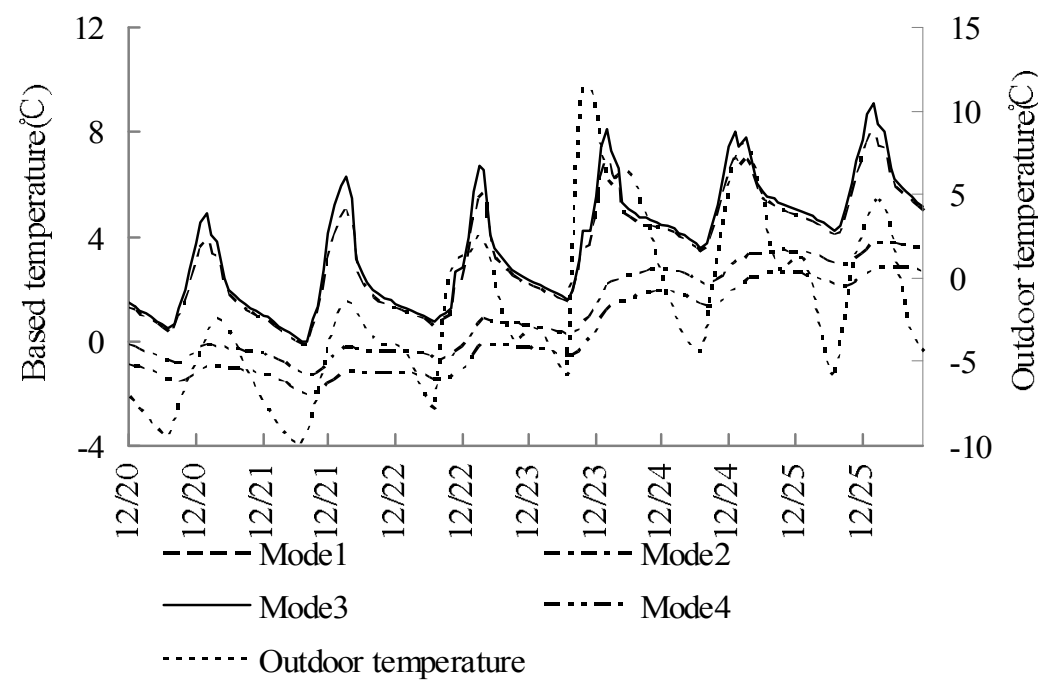

Fig.9 the Sun Room under Various Operation Modes Based Room Temperature

\section{Energy saving contribution rate of passive solar house}

Figure 11 has taken advantage of the reliability simulated by DeST software to imitate the based room temperature of the solar house and reference room in the heating season. During simulation process, the solar house and reference room are modeled by actual constructions. The solar house has no heat preservation at night and window of public wall is closed. The reference room has nothing further processing. 


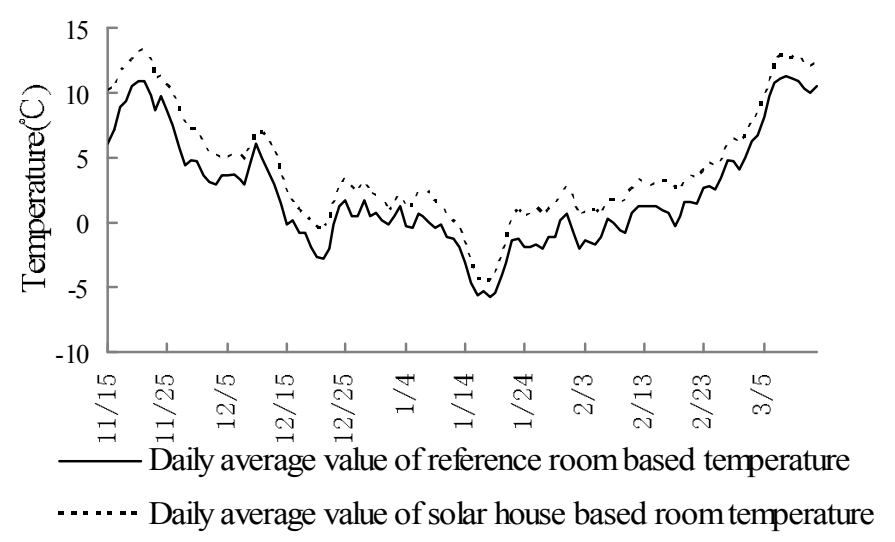

Fig.10 the Average indoor Temperature Solar House and Contrast Real Heating Season

From figure 10, we can see that the average value of based room temperature of solar house and reference room in heating season are respectively $4.24^{\circ} \mathrm{C}$ and $2.33^{\circ} \mathrm{C}$. The temperature difference is $1.91^{\circ} \mathrm{C}$. So solar house's energy saving effect is very obvious.

The solar house and the reference room conduct heating thermal load calculation, which mainly includes construction's heat transfer loss and cold air infiltration loss. Outdoor calculate temperature is $-3.8^{\circ} \mathrm{C}$ (from DeST database)which is the average outdoor temperature in the coldest January in Beijing area. Indoor heating temperature is $\mathrm{tn}=16^{\circ} \mathrm{C}$. According to these data in the above article, we can know that the heating thermal load of solar house is $\mathrm{Q} 1=4459 \mathrm{~W}$, and the reference room is $\mathrm{Q}=5896 \mathrm{~W}$.

Solar house's heating energy saving rate (ESF) is[12]

$$
\mathrm{ESF}=1-\mathrm{Q} 1 / \mathrm{Q}=24.3 \%
$$

From the above analysis, we can draw the conclusion that when the solar house and reference room maintain indoor heating temperature $16^{\circ} \mathrm{C}$, solar house needs less auxiliary heat and it can save heating energy $24.3 \%$.

\section{Conclusion}

We can draw conclusions as follows through testing and studying sunspaces-attaching passive solar house and the reference room in cold rural area in China:

(1)Sunspaces-attaching passive solar house in Beijing rural area has an apparent effect in improving indoor temperature in winter. During experiment, the largest indoor and outdoor temperature difference is $3.6^{\circ} \mathrm{C}$ and the smallest is $2.5^{\circ} \mathrm{C}$;

(2)According to simulation calculation, the optimized operation mode of sunspaces-attaching passive solar house in Beijing on sunny days in winter is to install night insulation curtain and increase ventilation of indoor rooms and sun space.

(3)According to simulation calculation, sunspaces-attaching passive solar house in Beijing area can improve room temperature $1.91^{\circ} \mathrm{C}$ in heating season. It is with significant ESF of $24.3 \%$. The energy saving effect is very obvious.

\section{Reference}

[1] Gao Jianwei, Zhu Neng, Ye Jiandong. Analysis of Suitable Energy Saving Measures of Residential Architecture in Beijing Rural Area [J], Journal of Tianjin University, 11 (2009) 420-423.

[2] Zhao Yan, Ye Jiandong. Energy Saving Transformation of Existing Constructions in Beijing 
Rural Area [J], Construction Technology, 5 (2010) 43-46.

[3] Liu Xianghong. Brief Analysis of Ecological Elements of Farmhouse in Beijing Rural Area [J], Agricultural Technology Service, 2 (2006), 164-166.

[4] Zhen Zhuling, Li Yonghong, Yang Xudong. Energy Saving Research on Beijing Rural Residence [J], ConstructionScience, 4 (2008) 9-14.

[5] Jian Yiwen, Zhu Zan, Shi Xingwang. Indoor Environment Study on Beijing Rural Residence [J], Construction Science, 6 (2010) 40-43.

[6] Yang Ming. Realization Mode and Key Technology Study on heating "Zero Energy Consumption" Farmhouse in North China [D], THU, 2011.

[7] Chen Mingdong, Shi Yuliang, Liu Xuebing. Heating Experiment Study on Sunspaces-Attaching Passive Solar House [J] Solar Energy Journal, 6 (2012) 944-947.

[8] Lu Chao, Tang Runing. Energy Saving Analysis of Sunspaces-Attaching Passive Solar House in High and Cold Area[J], National Construction Energy Saving Technology and Design Academic Council Memoir, 2005, 170-174.

[9] Liu Xiaoyan, Li Yuwen, Ma Changming, Xu Changjun, Wang Shuai. Comparison Analysis of Three Kinds of Passive Solar Houses in Daqing Area [J], Energy Saving Technology, 4 (2007) 334-336.

[10] M. Montoya, E. Pastor, E. Planas. Air Infiltration in Catalan Dwellings and Sealed Rooms: An experimental study, Building and Environment, 46 (2011) 2003-2011.

[11] Gu Hongyue, Cao Yiran, Yang Jianrong. Investigation on Ventilation Rate of Residence in Hot-Summer and Cold-Winter Zone [J], Residence Technology, 10 (2012) 36-39.

[12] Li Yuanzhe. Thermotechnical Design Manual of Passive Solar House[M]. Beijing: Tsinghua University Press, 1993. 